This PDF is a selection from an out-of-print volume from the National Bureau of Economic Research

Volume Title: Studies in Labor Markets

Volume Author/Editor: Sherwin Rosen, ed.

Volume Publisher: University of Chicago Press

Volume ISBN: 0-226-72628-2

Volume URL: http://www.nber.org/books/rose81-1

Publication Date: 1981

Chapter Title: Structural and Reduced Form Approaches to Analyzing Unemployment Durations

Chapter Author: Nicholas M. Kiefer, George R. Neumann

Chapter URL: http://www.nber.org/chapters/c13517

Chapter pages in book: (p. 171 - 186) 


\title{
5 \\ Structural and Reduced \\ Form Approaches to Analyzing Unemployment Durations
}

\author{
Nicholas M. Kiefer and George R. Neumann
}

\subsection{Introduction}

Workers with low current earnings comprise two types of individuals: those whose personal characteristics lead to their being permanently in the low-wage state, and those who are, owing to some exogenous event, only transitorily in the low-wage state. This distinction is recognized implicitly in public policies designed to aid such workers. Workers who are viewed as "permanent" low wage earners are provided programs which attempt to alter their personal characteristics-e.g., manpower training programs. For those workers viewed as only transitorily in the low earning state, services provided tend to be short-term income maintenance, e.g., unemployment insurance following losses in jobs and Workmen's Compensation following debilitating work injuries. The distinction between permanent and transitory is not rigid, however, since not all workers recover from a transitory shock such as the loss of a high-wage job. Similarly, some workers with characteristics normally associated with permanent low wage earnings escape to the high-wage sector. The size of the pool of low wage at any time depends then upon the magnitudes of these inflows and outflows. Although economists cannot claim to understand fully how public programs affect all movements between the two states, a clearer picture is emerging on the effects of manpower training programs and the movement out of the low-earnings state.

Our understanding of the effect of public programs on the transition into the low-earnings state is much less precise, however, partially because we have only a limited knowledge of the adjustments individuals

Nicholas M. Kiefer is Associate Professor of Economics, Cornell University.

George R. Neumann is Associate Professor of Economics, University of Chicago Graduate School of Business. 
make to such events as job loss. Why is it, for example, that one individual will become reemployed in a short time with only minimal loss of earnings while another individual with a similar earnings history finds a new job only after a considerable period of time and then experiences a substantial decline in earnings? Is this merely an example of "bad luck," or does it indicate a systematic means whereby a transitory event leads some workers into permanent low-wage status? Although much has been written on the job search behavior of individuals, comparatively little empirical evidence exists to shed light on why some individuals succeed and others fail. Moreover, the evidence that does exist is generally of little use for exploring questions about the efficacy of alternative labor market programs. This latter problem arises because customary approaches of analyzing the outcome of the job search process-that is, the wage offer accepted and the length of time required to obtain itproduce, at best, a reduced form relationship which confounds differences in market opportunities with differences in personal characteristics. Consequently, the true effect of a particular program is difficult to determine. For the purposes of policy analysis, an identification of the underlying structural relationship is necessary if one desires to measure the effects of programs designed to affect the job search process.

In this paper we consider the effects of two alternative labor market programs designed to smooth the transition from the unemployed state: a modified version of regular unemployment insurance and a wage subsidy program. In the data used in this study, one of these programs - the modified unemployment insurance-actually operated, and we can therefore consider variations in policy parameters. The alternative wage subsidy program was not available to any individuals, but it has attracted some attention recently as a means of reducing unemployment. While no direct evidence-that is, of the experiences of treatment and control groups-is available, we show that knowledge of the structural parameters-but not the reduced form parameters-is sufficient to identify the effects of this type of program. In examining the effects of the different programs, we contrast the policy implications that flow from the reduced form estimates and the structural estimates. These differences provide a useful insight into the gains obtainable from a precise model specification.

\subsection{Outcomes of the Job Search Process}

Analysis of the effects of unemployment has focused on the length of time required to find employment, and the resulting wage obtained; in particular, the analysis has focused on measuring the effects of programs such as unemployment insurance (UI) on the outcome of the job search 
process. The theory motivating this analysis is given by the well-known papers by Mortensen (1970) and McCall (1970) on search behavior. To state this theory somewhat loosely, empirical studies proceed from the observation that anything which lowers the cost of search increases an individual's reservation wage and thereby leads to both longer durations of unemployment and higher wages upon reemployment.

Empirical efforts to measure the relationship between duration and wage change have taken two directions. The first approach, typified by Classen (1977) and Ehrenberg and Oaxaca (1976), treats the outcomes of the job search process as jointly determined and attempts to estimate a reduced form system. The specific model is:

$$
\begin{aligned}
& D_{i}=X^{\prime}{ }_{1 i} B+E_{1 i} \\
& W_{i}=X_{2 i} B_{i}+E_{2 i}
\end{aligned}
$$

where $D_{i}$ is the number of weeks of unemployment and $W_{i}$ is reemployment wage. Parameters of the UI system, i.e., the replacement rate, are included in $X_{1}$ and $X_{2}$, and their coefficients are interpreted as the net effects of the UI system on the job search process.

An alternative approach has been taken in Kiefer and Neumann (1978 $1979 \mathrm{a} b$ ). In this approach the job search process is viewed as a selection problem following Heckman (1979). Individuals accept employment if and only if the market wage offer exceeds their reservation wage. Expected wages are then just a drawing from a truncated distribution, with the point of truncation depending upon the reservation wage, and the expected duration of unemployment is distributed geometrically about the inverse of the per period probability of finding an acceptable job offer. ${ }^{1}$ A difficulty encountered in the approach is that reservation wages are not observable; they must be inferred from the observed choices of individuals. This problem, which motivated the use of a reduced form solution in other papers, can be solved in the following manner (see also Kiefer and Neumann 1979b).

Assume that the wage offer distribution facing the ith individual is:

$$
\begin{aligned}
& \text { In } w_{i t}^{o}+X_{i}^{\prime} B+f_{i}+\varepsilon_{i t}^{o} \\
& \varepsilon_{i t}^{o} \sim \text { i.i.d. } N\left(0, \sigma_{o}^{2}\right) \forall t
\end{aligned}
$$

where $X_{i}$ represents all measured characteristics of an individual (age, education, labor market characteristics, etc.), $f_{i}$ represents all unmeasured characteristics, which are assumed known by the individual and potential employers, and $\varepsilon_{i t}^{o}$ is a random error term representing the "pure" amount of wage variability. The characterization in (2) implies that the wage offer distribution is stationary, an assumption which seems reasonable in light of the span of time covered by a typical spell of 
unemployment, and that observed wages have two sources of variationsystematic, but unmeasured, differences in "ability" $f_{i}$, and randomness in the wage offer process, represented by $\varepsilon_{i t}^{o}$.

Facing (2), an optimal strategy is to select a reservation wage with the property that offers which match or exceed this critical value are accepted and those that fall short are rejected. The reservation wage can be shown to be of the form:

$$
r_{i t}=g\left[F\left(w_{i}^{o}\right), m, \theta, t\right]
$$

where $F\left(w_{i}^{\rho}\right)$ is the distribution of wage offers, $m$ is the direct cost of search, $\theta$ is the discount factor, and $t$ represents the effect of state dependence - that is, reservation wages may systematically vary with the length of time searching. Using results from Kiefer and Neumann (1979a b), a first-order Taylor expansion of (3) can be shown to yield

$$
r_{i t}=k_{i}\left(X_{i}^{\prime} B+f_{i}\right)+Z_{i}(t) \cdot \gamma
$$

where $k_{i}$ is defined as

$$
k_{i}=\frac{\int_{r_{i t}}^{\infty} F\left(w_{i}^{o}\right) d w^{o}}{\int r_{i t}^{\infty} F\left(w_{i}^{o}\right) d w^{o}+\theta}=\frac{\alpha_{i}}{\alpha_{i}+\theta}=k_{i}\left(X B, Z \gamma, k_{i}\right)
$$

Note that there is no stochastic element in $\left(3^{\prime}\right)$; individuals who search optimally in this model choose a strategy-a reservation price-which is not random, although it may vary over time as reflected in the time subscript on $Z$, i.e., in response to time-dependent factors which directly affect the costs of search.

Individuals accept employment if and only if the wage offer exceeds the reservation wage. Using (2) and ( $\left.3^{\prime}\right)$, the employment condition is that

$$
s_{i}(t)=\left(1-k_{i}\right)\left(X_{i}^{\prime} B+f_{i}\right)-Z_{i}(t) \gamma>-\varepsilon_{i}^{o}
$$

defining $s_{i}(t)=-\left[\left(1-k_{i}\right)\left(X_{i}^{\prime} B+f_{i}\right)-Z_{i}(t) \gamma\right] / \sigma$. The probability of finding a job in any period $\alpha$ is, for a given individual,

$$
\alpha\left[s_{i}(t) \mid f_{i}\right]=\operatorname{Pr}\left(w_{i}^{o}>w_{i}^{r} \mid f_{i}\right)=1-\Phi\left[s_{i}(t) \mid f_{i}\right]
$$

where $\Phi$ is the standard normal distribution function. The statement in (5) is the probability of an individual's finding a job in period $t$, conditional on his unmeasured ability $f_{i}$. Although by definition we do not have measures of $f_{i}$, an implication of the optional choice of a reservation wage is that randomness in wage offers should be independent of $f_{i}$. Hence the unconditional probability of finding an acceptable job offer is

$$
\alpha\left[s_{i}(t)\right]=\int_{-\infty}^{\infty}\left[1-\Phi\left(s_{i} \mid f_{i}\right)\right] d \Phi\left(\frac{f_{i}}{\sigma_{F}}\right)
$$


Using (6) and results from conditional normal theory, the probability of observing a particular outcome-that is, a wage $w_{i}^{o}$, and a length of unemployment $D_{i}$-is given by

$$
\begin{aligned}
\operatorname{Pr}\left(w_{i}^{o}, D_{i}\right)= & \int_{-\infty}^{\infty}\left(\left\{\Pi \Phi\left[s_{i}(t) \mid f_{i}\right]\right\} \cdot \frac{1}{\sigma_{o}} \phi\left(\varepsilon_{i}\right) .\right. \\
& {\left[1-\Phi\left(s_{i} \mid f_{i}\right]\right) d \Phi\left(\frac{f_{i}}{\sigma_{F}}\right) }
\end{aligned}
$$

as $t$ goes from 1 to $D_{i}-1$ and $d \phi\left(f_{i} / \sigma_{F}\right)$ goes from $-\infty$ to $\infty$. Subject to identification criteria discussed in Kiefer and Neumann (1979a b), all parameters in equation 7 can be estimated by maximum likelihood methods. ${ }^{2}$ In particular one can identify $B, \gamma, \sigma_{o}^{2}$ (the pure variation in wage offers), and $\sigma_{F}^{2}$ (the variation in unmeasured ability).

The issues which arise in estimating the model described above are discussed at length elsewhere (see Kiefer and Neumann 1979b). For the present purposes it is sufficient to note that two structural equations relating unemployment and reemployment earnings are embedded in (7). The expected length of search for a randomly chosen individual is given by:

$$
\begin{aligned}
E\left(D_{i}\right)= & \sum_{j=1}^{\infty} \int_{-\infty}^{\infty}\left(\prod_{\ell=1}^{j} \Phi\left[s_{i}(\ell) \mid f_{i}\right]\right) \\
& {\left[1-\Phi\left(s_{i}(j) \mid f_{i}\right] \cdot j d \Phi\left(\frac{f_{i}}{\sigma}\right)\right.}
\end{aligned}
$$

The expected reemployment wage is somewhat more cumbersome to derive. Conditional on $f_{i}$, and conditional on the length of search being $D_{i}$, expected reemployment earnings are:

$$
E\left(w_{i}^{o} \mid f_{i}, D_{i}\right)=X_{o}^{\prime} B+f_{i}+\sigma_{o} \lambda\left[s(D) \mid f_{\mathrm{i}}\right]
$$

where

$$
\gamma\left[s(D) \mid f_{i}\right]=\frac{\phi\left[s_{i}(D) \mid f_{i}\right]}{1-\Phi\left[s_{i}(D) \mid f_{i}\right]}
$$

If the reservation wage were constant, i.e., $s$ did not vary with $D$, then unconditional expected earnings would be given by

$$
\begin{aligned}
E\left(w_{i}^{o}\right) & =\int_{-\infty}^{\infty} E\left(w_{i} \mid f_{i}, D\right) d \Phi\left(\frac{f_{i}}{\sigma}\right) \\
& =X_{i}^{\prime} B+\sigma_{o} \int_{-\infty}^{\infty} \lambda\left(s_{i} \mid f_{i}\right) d \Phi\left(\frac{f_{i}}{\sigma}\right)
\end{aligned}
$$

When reservation wages vary with search time, the second term on the 
right-hand side on (10) must be modified to allow for differences in the probability of receiving an acceptable offer in a given period. Define the probability that an acceptable offer is received in period $j$ as:

$$
g_{i}(j)=\left(\prod_{\ell=1}^{j-1} \Phi\left[s(\ell) \mid f_{i}\right]\right) \cdot 1-\Phi\left[s(j) \mid f_{i}\right]
$$

The unconditional expected reemployment wage is then:

$$
\begin{aligned}
E\left(w_{i}^{o}\right) & =\int_{-\infty}^{\infty}\left(\sum_{j=1}^{\infty} E\left(w_{i}^{o} \mid f_{i}, D=j\right) \cdot g_{i}(j)\right) d \Phi\left(\frac{f_{i}}{\sigma_{o}}\right) \\
& -X_{i}^{\prime} B+\sigma_{o} \cdot \int_{-\infty}^{\infty}\left(\sum_{j=1}^{\infty} \lambda\left[s_{i}(j) \mid f_{i}\right] \cdot g_{i}(j)\right) d \Phi\left(\frac{f_{i}}{\sigma_{o}}\right)
\end{aligned}
$$

Equations 8 and 12 can be thought of as the structural analogues to what we have termed the reduced form solutions of (1a) and (2b). In view of the differences between the reduced form and structural approaches it is useful to examine the merits of each. Two issues are of particular importance: interpreting changes in policy variables such as UI benefits, and drawing inferences from incomplete samples (see Johnson and Kotz 1972; Heckman, in press).

The reduced form approach has one particular advantage-it is simple and cheap to estimate. If reservation wages are constant, the estimated coefficients have a potential interpretation as the coefficients of a Taylor expansion of the inverse of (6) for the duration equation [i.e., $E(D)$ $\left.=1 / \alpha\left(s_{i}\right)\right]$, and as

$$
B+\sigma_{o} \int_{-\infty}^{\infty} \frac{\partial \gamma(\cdot)}{\partial(\cdot)} \frac{\partial(\cdot)}{\partial r} \frac{\partial n}{\partial X_{i}} d \Phi\left(\frac{f_{i}}{\sigma}\right)
$$

for the earnings equation. In this case, if both forms of the job search model were estimated on a complete sample, the only difference that should arise would be due to the inherent nonlinearity of the structural duration equation. If reservation wages vary over time as well as across individuals, then the correspondence between the two approaches is less obvious. Policies which affect the duration of unemployment also affect the distribution of accepted wages since the point of truncation varies with duration.

The use of a reduced form approach also results in problems of interpretation when certain types of policy simulations are attempted. For example, if a wage subsidy of, say, ten percent were given to all individuals in the sample, it would affect both duration and reemployment earnings, although in opposite ways. In the absence of a controlled experiment-where individuals were randomly assigned to the group receiving the subsidy-it is difficult to see how one could simulate this effect using a reduced form model. The problem is one of identification: 
the moments of the wage distribution do not enter explicitly into the reduced form approach. If reservation wages are constant, this problem may not be serious because of the potential interpretation of the reduced form coefficients noted above. In the more general case, however, it is not possible to infer the results of such an experiment from the reduced form estimates.

Perhaps the greatest difference between the two approaches arises when information is available only for an incomplete sample. For example, it is frequently the case that a "follow-up" survey is performed after some event has occurred. At the time of the survey some individuals will have completed their job search, but some will not. Those who have not found employment will tend to have low expected market earnings, relative to their reservation wage--hence the long period of unemployment. Since neither of the dependent variables is observed, the observations are usually excluded from the analysis. ${ }^{3}$ For well-known reasons this is likely to result in biased estimates. Apart from the question of bias, there is the question of interpreting the results of any simulation exercise since the composition of an incomplete sample is not likely to be invariant under changes in policy. Consider, for example, the effect of a shift in the mean of the wage offer distribution. Search theory implies that the expected wage should increase, and expected duration decrease, for all individuals. In an incomplete sample, the effect of such a policy would be that some individuals who previously had not found employment would become employed and hence would be included in the sample. If these individuals on average had higher durations of unemployment and lower expected earnings, then observed average wages would fall and duration increase, even in a carefully controlled experiment.

The importance of this effect will depend upon the location of reservation wages along the distribution of wage offers. If reservation wages are high, relative to the mean of the wage offer distribution, and if the distribution of offers has small variance, even a small shift in the mean may produce a significant change in unemployment patterns.

In noting these differences, we have only pointed out the potential problems which may exist; the severity of these problems - that is, the extent to which they lead to different policy implications-is ultimately an empirical matter. In the following section, we examine the simulated responses of a group of individuals to two plans which affect their unemployment activities.

\subsection{Simulating Job Search Behavior: The Effects of A Wage Subsidy Plan}

In this section we apply the models discussed above to a sample of unemployed male workers. This particular sample was generated from a 
survey of trade-displaced workers conducted by the Institute for Research on Human Resources of the Pennsylvania State University. A complete description of the data source is contained in Neumann (1978). Several features make this group particularly appropriate for discussions about low-wage workers. The sample is constructed solely of individuals who were permanently separated from employment-in most cases because the entire plant shut down. Thus we observe only job search behavior and do not have to be concerned with responses to anticipated, temporary layoffs. Moreover, the nature of the shock conforms to the idea of an exogenous shock to which some individuals adjust reasonably well, and others adjust only with great difficulty. Although many of these individuals would not have been considered low-wage workers prior to displacement, the average loss in weekly earnings upon reemployment was over twenty-five percent: consequently, most would be considered low-wage earners afterward. Summary statistics on this sample are contained in table 5.1.

Estimates of the reduced form equations for duration and reemployment earnings are presented in table 5.2, and the structural estimates of reemployment earnings (wage offers) and reservation wages are contained in table 5.3. Although we will not dwell on the precision of the estimates, we do note that the explanatory power of the OLS regression of unemployment duration is exceedingly small; this appears to be a common finding (see, e.g., Ehrenberg and Oaxaca 1976; Classen 1977).

Both approaches indicate an effect of UI benefits on the outcome of the job search process. The reduced form estimates imply that a ten percent increase in the replacement rate-equivalent here to an average increase of $\$ 14.9$ per week in UI benefits - would lead to an increase in duration of about one-half week $(.0314 \times 14.9)$, and an increase in unemployment earnings of 0.60 percent. The effects of increased UI benefits are apparent in column 2 , but the numerical values of the increases in duration and reemployment earnings depend upon the position of the reservation

Table 5.1

Sample Characteristics of Male Workers

\begin{tabular}{lccc}
\hline & Mean & Maximum & Minimum \\
\cline { 2 - 4 } Education (years) & 10.2 & 21.0 & 0.0 \\
No. of dependents & 1.7 & 9.0 & 0.0 \\
Percent married & 83.5 & - & - \\
Percent union members & 70.4 & - & - \\
Local unemployment rate at layoff (\%) & 5.30 & 9.00 & 2.20 \\
Age & 47.8 & 75.0 & 19.0 \\
Unemployment benefits per week (\$1967) & 62.7 & 117.11 & 0.0 \\
Maximum benefit period (weeks) & 41.5 & 65.6 & 0.0 \\
Previous weekly earnings (\$1967) & 149.0 & 457.0 & 19.20 \\
\hline
\end{tabular}


Table 5.2 Reduced Form Estimates of Duration and Reemployment Wage Equation

\begin{tabular}{|c|c|c|}
\hline & $\begin{array}{l}\text { Duration } \\
\text { (1) }\end{array}$ & $\begin{array}{l}\text { Reemployment } \\
\text { Earnings } \\
\text { (2) }\end{array}$ \\
\hline Constant & $\begin{array}{l}18.1566 \\
(2.17)\end{array}$ & $\begin{array}{r}1.839 \\
(3.16)\end{array}$ \\
\hline Education & $\begin{array}{c}0.0161 \\
(0.96)\end{array}$ & $\begin{array}{l}0.0088 \\
(2.41)\end{array}$ \\
\hline Dependents & $\begin{array}{c}0.0261 \\
(0.41)\end{array}$ & $\begin{array}{c}0.0617 \\
(0.14)\end{array}$ \\
\hline Tenure & $\begin{array}{c}0.0040 \\
(1.06)\end{array}$ & $\begin{array}{c}-0.0069 \\
(1.92)\end{array}$ \\
\hline Marital status & $\begin{array}{c}0.0001 \\
(0.00)\end{array}$ & $\begin{array}{c}0.1139 \\
(0.60)\end{array}$ \\
\hline Unemployment rate & $\begin{array}{l}2.1164 \\
(1.97)\end{array}$ & $\begin{array}{c}-0.0461 \\
(1.27)\end{array}$ \\
\hline Age & $\begin{array}{c}+0.0441 \\
(1.40)\end{array}$ & $\begin{array}{l}0.0210 \\
(1.21)\end{array}$ \\
\hline $\mathrm{Age}^{2}$ & $\begin{array}{c}-0.0003 \\
(0.27)\end{array}$ & $\begin{array}{c}-0.0002 \\
(0.06)\end{array}$ \\
\hline Ed $\cdot$ Age & $\begin{array}{c}+0.0143 \\
(0.20)\end{array}$ & $\begin{array}{c}-0.0011 \\
(1.61)\end{array}$ \\
\hline UI benefits & $\begin{array}{c}0.0314 \\
(1.71)\end{array}$ & $\begin{array}{l}0.0004 \\
(1.30)\end{array}$ \\
\hline Maximum duration & $\begin{array}{c}0.0214 \\
(1.40)\end{array}$ & $\begin{array}{c}-0.0001 \\
(0.01)\end{array}$ \\
\hline $\ln \left(W_{t-1}\right)$ & $\begin{array}{c}-0.3118 \\
(1.11)\end{array}$ & $\begin{array}{c}0.5406 \\
(7.24)\end{array}$ \\
\hline $\begin{array}{l}R^{2} \\
F\end{array}$ & $\begin{array}{l}.1331 \\
1.478\end{array}$ & $\begin{array}{l}.2480 \\
9.012\end{array}$ \\
\hline
\end{tabular}

wage in the wage offer distribution. We calculate these effects in the simulation reported below.

Before examining the simulation results it is useful to consider one feature of the job search process. Both casual empirical evidence and some previous studies (e.g., Neumann 1978) suggest that losses due to unemployment are greatest for the long-term unemployed. Although a higher reservation wage leads to higher expected reemployment and a greater length of unemployment for any individual ex ante, when one observes the outcomes of the job search process ex post, this investment 


\begin{tabular}{|c|c|c|}
\hline & $\begin{array}{l}\text { Earnings Function } \\
\text { (1) }\end{array}$ & $\begin{array}{l}\text { Reservation } \\
\text { Wage Function } \\
\text { (2) }\end{array}$ \\
\hline Constant & $\begin{array}{l}2.8263 \\
(6.24)\end{array}$ & $\begin{array}{l}1.9713 \\
(3.47)\end{array}$ \\
\hline Education & $\begin{array}{l}0.0361 \\
(1.87)\end{array}$ & $\begin{array}{l}0.0101 \\
(1.27)\end{array}$ \\
\hline Dependents & - & $\begin{array}{c}-0.0068 \\
(0.47)\end{array}$ \\
\hline Tenure & $\begin{array}{c}-0.0078 \\
(3.68)\end{array}$ & - \\
\hline Marital status & - & $\begin{array}{c}-0.0824 \\
(3.68)\end{array}$ \\
\hline Unemployment rate & $\begin{array}{l}0.0197 \\
(1.68)\end{array}$ & $\begin{array}{l}0.0161 \\
(2.89)\end{array}$ \\
\hline Age & $\begin{array}{l}0.0194 \\
(1.86)\end{array}$ & $\begin{array}{l}-0.0127 \\
(3.46)\end{array}$ \\
\hline $\mathrm{Age}^{2}$ & $\begin{array}{c}-0.0001 \\
(0.61)\end{array}$ & $\begin{array}{l}0.0001 \\
(0.84)\end{array}$ \\
\hline Ed·Age & $\begin{array}{c}-0.0008 \\
(1.87)\end{array}$ & $\begin{array}{c}-0.0003 \\
(1.71)\end{array}$ \\
\hline Unemployment benefits & - & $\begin{array}{l}0.0016 \\
(2.43)\end{array}$ \\
\hline Maximum duration & - & $\begin{array}{l}0.0004 \\
(0.59)\end{array}$ \\
\hline$\ell n W_{t-1}$ & $\begin{array}{l}0.2574 \\
(4.57)\end{array}$ & - \\
\hline$F_{i}$ & - & $\begin{array}{l}-0.0014 \\
(0.91)\end{array}$ \\
\hline$t$ & - & $\begin{array}{l}-0.0023 \\
(2.01)\end{array}$ \\
\hline$\sigma_{w^{0}}$ & $\begin{array}{l}0.0283 \\
(2.62)\end{array}$ & \\
\hline$\sigma_{F}^{2}$ & $\begin{array}{c}0.2493 \\
(12.41)\end{array}$ & \\
\hline$\ell n \ell \ell$ & $-1,794.83$ & \\
\hline
\end{tabular}

Note: $t$-statistics in parentheses. 
aspect is swamped by variations in individual characteristics and by random errors in the process. In the present context this phenomenon is likely to be concentrated among the group of workers who had not found employment by the survey date. Since their behavior is of particular interest in any discussion of low-income workers we present simulation results separately for this group.

The simulated effects of changing UI benefits in steps of five percent on duration of unemployment and the percentage change in reemployment earnings are presented in table 5.4. Panels A and B contain the estimates from the reduced form model (equations $1 \mathrm{a}$ and $1 \mathrm{~b}$ ) for the total sample and for those workers who remained unemployed for at least sixty-five weeks; panels $C$ and $D$ contain the equivalent estimates for the structural model (equations 8 and 12). The estimates in table 5.4 show two pronounced patterns. Looking across each panel, we see that, for this sample at least, changes in UI benefit levels would have almost negligible effects. Increasing UI benefits by twenty percent-which for this sample is equivalent to raising the average replacement rate by 8.4 percentage points (from 42.1 percent to 50.5 percent) -would raise reemployment earnings by only about .5 percent and increase the duration of unemployment by about one-half week. These are quite modest effects when one considers that the average reemployed worker in this sample had a decline in real weekly earnings of 26.7 percent and spent 39.1 weeks unemployed. It is interesting to note that although estimates of the precise effect of changing UI benefits would differ depending upon whether one used the reduced form or structural model, the conclusions to be drawn from the evidence would not.

Looking down the columns of table 5.4, we observe a somewhat different picture of the differences between the two approaches to modeling the job search process. Comparison of panels $A$ and $B$ would seem to indicate that there is little difference between those who had not become employed within 65 weeks and those who had; panels C and D indicate the contrary. The expected duration of unemployment was estimated to be 34.7 weeks for those who became employed within 65 weeks, and 47.2 weeks for those who had not become employed by 65 weeks. This amounts to about a seven-week difference in expected duration of unemployment between the two groups. In one sense, this difference between the two models can be considered a contrived one, since the structural model takes into account information on the characteristics and, partially, the job search outcomes, of the group of workers who had not found jobs within 65 weeks. ${ }^{4}$ But this is precisely the purpose of a structural model, and the differences observed in table 5.4 represent the basis for using such an approach to design policies to smooth labor market transitions. Under the reduced form approach, the similarity of the estimated duration and wage changes would lead one to conclude that 
Table 5.4

Structural and Reduced Form Simulations of the Efrect of Alternative Levels of UI Benefits

\begin{tabular}{|c|c|c|c|c|c|}
\hline & \multicolumn{5}{|c|}{$\% \Delta$ in UI Benefits } \\
\hline & 0.0 & 5.0 & 10.0 & 15.0 & 20.0 \\
\hline \multicolumn{6}{|c|}{$\begin{array}{l}\text { Reduced Form Estimates } \\
\text { A. Total Sample }\end{array}$} \\
\hline Duration (weeks) & 39.31 & 39.41 & 39.51 & 39.61 & 39.72 \\
\hline$\% \Delta$ in earnings & 0.0 & 0.13 & 0.25 & 0.38 & 0.50 \\
\hline \multicolumn{6}{|c|}{ B. Unemployed after 65 weeks } \\
\hline Duration (weeks) & 39.62 & 39.73 & 39.83 & 39.93 & 40.03 \\
\hline$\% \Delta$ in earnings & 0.0 & 0.13 & .025 & 0.37 & 0.49 \\
\hline \multicolumn{6}{|c|}{$\begin{array}{l}\text { Structural Estimates } \\
\text { C. Total sample }\end{array}$} \\
\hline Duration (weeks) & 43.10 & 43.41 & 43.67 & 43.85 & 43.91 \\
\hline$\% \Delta$ in earnings & 0.0 & 0.17 & 0.29 & 0.46 & 0.54 \\
\hline \multicolumn{6}{|c|}{ D. Unemployed after 65 weeks } \\
\hline Duration (weeks) & 47.21 & 47.36 & 47.50 & 47.61 & 47.71 \\
\hline$\% \Delta$ in earnings & 0.0 & 0.11 & 0.18 & 0.25 & 0.31 \\
\hline
\end{tabular}

the two groups are essentially the same; hence it must be random influences-luck - which determine whom the labor market assigns to each group. The structural approach, on the other hand, implies that there are real differences between the two groups and thus, at least in principle, allows the possibility of predicting in advance what types of individuals are likely to be most affected by unexpected job loss.

The results of this simulation raise strong doubts about the ability of what is essentially an income maintenance program to have a significant impact on the reemployment experience of displaced workers. Although the sample used is unique, and certainly not representative of all unemployed workers, our results, both the reduced form and structural versions, are not significantly at odds with the findings of others which are based solely on a reduced form approach. While it is difficult to generalize from a sample of one, there is at least the suggestion that returns from more precise modeling of the job search process may be important for policy purposes.

Although predicting which types of individuals will be most adversely affected by job termination is one possible gain to a structural approach, a more important gain is likely to be in terms of the number of difference policy options which can be considered. As an example, we consider the option of a wage subsidy program. The basic idea of a wage subsidy is to shift the distribution of wage offers facing individuals, thereby making employment more likely. In the reduced form approach there is no 
obvious way to incorporate such effects, except possibly through a controlled experiment. A structural approach allows for a direct interpretation, however, since the shift in the wage offer distribution affects an individual's expected earnings both directly-i.e., through $X_{i}^{\prime} B$-and indirectly through its effects on reservation wages.

In table 5.5 we present the results of a simulation exercise with varying amounts of wage subsidy. Because these simulations, as in the case of the UI subsidy, are partial equilibrium in nature, the results are sensitive to the assumed stability of the wage offer distribution. In the present case, this amounts to assuming that a wage subsidy program will not affect the distribution of wage offers part from the mean shift, i.e., no "extra" effects due to a substitution of labor for capital. For small programs this assumption seems tenable.

The issue also arises of how accurately this shift in the distribution is perceived by individuals. If it is fully perceived, then reservation wages rise by a fraction $\alpha / \alpha+\theta$ of the increase in the mean. This increase in reservation wages leads to lengthier search, and, consequently, the effect on duration of unemployment is lessened. Since some wage subsidy plans (e.g., jobs credit) work in a manner that may not be obvious to individuals, we present estimates of the effect on duration assuming full reservation wage change (panels $A$ and $B$ ), and no reservation wage change (panel C).

In contrast to a UI subsidy, a direct wage subsidy appears to have quite significant effects on the job search process. From panels $A$ and $B$ we observe that a twenty percent wage subsidy would lead to an increase in reemployment earnings of about nineteen percent, and a reduction of unemployment duration of about a week, if the shift in the mean is

Table 5.5

Structural Simulations of the Effect of a Wage Subsidy Program

\begin{tabular}{|c|c|c|c|c|c|}
\hline & \multicolumn{5}{|c|}{$\% \Delta$ in Mean Wage Offer } \\
\hline & 0.0 & 5.0 & 10.0 & 15.0 & 20.0 \\
\hline \multicolumn{6}{|c|}{ A. Total Sample } \\
\hline Duration (weeks) & 43.10 & 42.87 & 42.51 & 42.23 & 42.06 \\
\hline$\% \Delta$ in earnings & 0.0 & 4.91 & 9.84 & 14.72 & 19.6 \\
\hline \multicolumn{6}{|c|}{ B. Unemployed over 65 weeks } \\
\hline Duration (weeks) & 47.21 & 47.03 & 46.74 & 46.39 & 46.12 \\
\hline$\% \Delta$ in earnings & 0.0 & 4.87 & 9.78 & 14.68 & 19.2 \\
\hline \multicolumn{6}{|c|}{$\begin{array}{l}\text { C. Duration of Unemployment with } \\
\text { Incomplete Knowledge (weeks) }\end{array}$} \\
\hline Total sample & 43.10 & 41.64 & 40.02 & 38.75 & 37.29 \\
\hline $\begin{array}{l}\text { Unemployed over } \\
65 \text { weeks }\end{array}$ & 47.21 & 45.88 & 44.16 & 42.82 & 41.28 \\
\hline
\end{tabular}


completely perceived. The effect of the change in reservation wages can be seen clearly in panel $\mathrm{C}$ : if reservation wages did not adjust, expected unemployment duration would decrease by six weeks instead of one.

\subsection{Conclusion}

This paper has focused on two points - the inferences which can be obtained from structural versus reduced form analysis of the outcome of the job search process, and the effects of two subsidy programs on the job search process. In regard to the former topic, it is clear that a structural model permits a wider range of possible questions. In particular, it is possible to consider, ex ante, what the likely experience of a given cohort of job searchers will be, and, in principle, to tailor different types of programs to ease their labor market transitions.

The comparison of a UI subsidy with a wage subsidy revealed significant differences. Higher levels of UI payments led, as expected, to both longer durations of unemployment and higher reemployment earnings. Both effects were quite small, however, and, at least for low-wage workers similar to the individuals in this sample, there is little reason to believe that programs which emphasize income maintenance are likely to have much impact on the types of jobs obtained. By contrast, a wage subsidy program appears to have a significant effect on reemployment earnings, and also to lead to a moderate decline in duration. This is a one-blade-of-the-scissors result of course, and it is subject to criticism on those grounds. Nonetheless, for relatively small programs, the possibilities appear to be fruitful.

\section{Notes}

1. This result holds only for the case of constant reservation wages. The correct distribution of durations for the general use is given in equation (7) below.

2. The identification criteria amount to the following: some variable(s) must affect wage offers but must not directly affect reservation wages. Indirect effects-e.g., through the moments of the wage offer function-are permissible, indeed necessary.

3. There are other reasons why truncation could occur. Using state UI records on compensated unemployment results in a truncation of those with very short durations-less than the waiting period-and those with long durations-those whose unemployment exceeds the maximum duration period.

4. The estimates in the reduced form approach for the sample of workers not employed in sixty-five weeks are constructed simply by using the observed characteristics of the individual and the coefficients estimated from the sample of employed. No attempt is made to adjust the constant term such that the expected value of, say, duration reflects the obvious fact that the observed period of unemployment was greater than 65 weeks. 


\section{References}

Classen, K. "The Effect of Unemployment Insurance on the Duration of Unemployment and Subsequent Earnings." Industrial and Labor Relations Review 30, no. 4 (July 1977): 438-44.

Ehrenberg, R., and Oaxaca, R., "Unemployment Insurance, Duration of Unemployment, and Subsequent Wage Gain." American Economic Review 66 (December 1976): 754-66.

Heckman, J. "Sample Selection Bias as a Specification Error." Econometrica 47 (January 1979): 153-62.

Johnson, N., and Kotz, S. Distributions in Statistics. Vol. 4: Continuous Multivariate Distributions. N.Y.: John Wiley, 1972.

Kiefer, N., and Neumann, G. "Estimation of Wage Offer Distributions and Reservation Wages," in S. Lippman and J. McCall, eds., Studies in the Economics of Search. Amsterdam: North-Holland, 1978, pp. 17189.

"An Empirical Job Search Model with a Test of the Constant Reservation Wage Hypothesis." Journal of Political Economy 87, no. 1 (February 1979a).

"Individual Effects in a Nonlinear Model: Explicit Treatment of Heterogeneity in the Empirical Job-Search Model." Mimeo., February 1979.

McCall, J. "Economics of Information and Job Search." Quarterly Journal of Economics, February 1970, pp. 113-26.

Mortensen, D. "Job Search, the Duration of Unemployment, and the Phillips Curve," American Economic Review 60 (December 1970): pp. $847-62$.

Neumann, G. "The Labor Market Adjustments of Trade Displaced Workers: The Evidence from the Trade Adjustment Assistance Program," in R. Ehrenberg, ed., Research in Labor Economics, pp. 353-81. JAI Press, 1978. 
This Page Intentionally Left Blank 